\title{
Drought Regionalization Based on Low Flow Trends in Selected River Basins in Slovakia
}

\author{
M. Zeleňáková, T. Sol'áková, P. Purcz, D. Simonová, and Ž. Kuzevičová
}

\begin{abstract}
An important function in both engineering hydrology and integrated catchment area management is performed by statistical analysis. This paper presents the trend analysis of low water flows in selected rivers in Eastern Slovakia. There are many statistical methods for data evaluation. The most of useful, presented in this paper, is the non-parametric Mann-Kendall test. This analysis was carried out for statistical data from 63 river stations lying in the eastern part of Slovakia, namely in Hornád, Poprad, Bodva, Bodrog river basins. The data were obtained from the Slovak Hydrometeorological Institute, Regional Centre Košice. Because the low flow data are not comparable for the individual stations, normally it is only possible to do the statistical analysis for each river station separately. The relative sizes of the low stream flow trends in individual river stations were calculated as directives of the trend lines. Using ArcView GIS was created thematic map from geographical map of Eastern Slovakia and was performed hydrological drought risk regionalization.
\end{abstract}

Index Terms-Hydrological drought, low flow, Mann-Kendall test, river station, trend analysis.

\section{INTRODUCTION}

Droughts rank first among all natural hazards when measured in terms of the number of people affected. Although as a natural hazard, droughts differ from other natural hazards in several ways. First, the onset and the end of a drought are difficult to determine, the impacts of a drought increase slowly, often accumulate over a considerable period and may linger for years after termination. Second, it is difficult to define a drought which leads to confusion for not having a universal definition of drought. Third, drought impacts are non-structural and spread over large geographical areas than damages that may result from other natural hazards [1]. In contrast to floods, hurricanes, earthquakes, and tornadoes a drought affects water bodies of water resources structures and it seldom results in structural damage. The quantification of the drought impact is far more difficult than for other natural hazards. Fourth, human

Manuscript received March 19, 2014; revised May 22, 2014. The Centre was supported by the Slovak Research and Development Agency under the contract No. SUSPP-0007-09.

M. Zeleňáková is with the Technical University of Košice, Institute of Environmental Engineering, Vysokoškolská 4, 04200 Košice, Slovakia (corresponding author's tel: +421-55-602 4270; e-mail: martina.zelenakova@tuke.sk).

P. Purcz, T. Soláková, and Ž. Kuzevičová are with the Technical University of Košice, Slovakia (e-mail: pavol.purcz@tuke.sk, tanik@post.sk, zofia, kuzevicova@tuke.sk).

D. Simonová is with the Slovak Hydrometeorological Institute, Ďumbierská 26, 04200 Košice, Slovakia (e-mail dorota.simonova@shmu.sk). activities can directly trigger a drought unlike other natural hazards, with exacerbating factors such as overfarming, excessive irrigation, deforestation, over-exploiting available water, and erosion, adversely impacting the ability of the land to capture and hold water [2].

Depending on where it shows a lack of water by the World Meteorological Organization [3] classifies four basic types of drought, including: meteorological, hydrological, agricultural and socio-economic droughts [2]. The drought effects have been observed on all continents and over the past decade the frequency of drought increases.

Hydrological drought is a phenomenon which rise with existence of occurrence of no- precipitation period coupled with extreme temperatures. The genesis of hydrological extremes also affects the morphological conditions of origin, climatic factors, geological and hydrogeological conditions and anthropogenic activities [4], [5]. This type of drought is defined by long-term decrease in levels of surface water bodies (e.g. rivers, lakes, reservoirs and other) and drops in groundwater levels [6]. Low water content is proof of this type of drought [7]. On the mathematical-statistical evaluation of low water content are used to the flow and no-flow characteristics [8]. Low flow is defined as the smallest untouched average daily flow volume in time.

There is a distinction made between stream flow droughts and low flows (minimal flows). The main feature of a drought is said to be the deficit of water for some specific purpose. Low flows are normally experienced during a drought, but they feature only one element of the drought, i.e. the drought magnitude. Low flow studies are described as being analyses aimed at understanding the physical development of flows at a point along a river at a short-term (e.g. daily). Hydrological drought analyses in terms of stream flow deficits are said to be studies over a season or longer time periods and in a regional context. A stream flow drought event definition quantitatively defines whether the flow can be regarded as being in a drought situation or not and gives the duration of a drought, whereas low flow indices characterise specific features of the low flow range [9].

During the past decades, many parametric and nonparametric techniques for the detection of long-term trends in time series were developed and applied [10]. A discussion on whether to choose a parametric or non-parametric test can be found in [11]. In the present study the widely used non-parametric tests was applied: the Mann-Kendall test, which is also recommended by the World Meteorological Organization [3]. The non-parametric Mann-Kendall statistical test has been effectively and the most used to assess the significance of trend in hydrological time series [12]-[14].

A number of recent studies have identified trends in 
streamflows. Despite several reports on recent droughts in Europe, the non-parametric Mann-Kendall test and a resampling test for trend detection in the paper [10] was showed that it is not possible to conclude that drought conditions in general have become more severe or frequent. The period analysed and the selection of stations strongly influenced the regional pattern. It was also proved in the study [15] that investigates streamflow trends in a newly-assembled, consolidated dataset of near-natural streamflow records from 441 small catchments in 15 countries across Europe. It elucidated spatial patterns and regional variability of streamflow trends. Trends were calculated by the slopes of the Kendall-Theil robust line for standardized annual and monthly streamflow, as well as for summer low flow and low flow timing.

Burn and Elnur [12] utilizes the Mann-Kendall non-parametric test to detect trends in hydrologic variables for Canadian catchments. There were found differences in the geographic location of significant trends. Douglas et al. [16] were evaluated trends in flood and low flows in the US using a regional average Kendall's trend test. They found evidence of upward trends in low flows at the larger scale in some of the Midwest regions.

In [17] the existence of trend in maximum, mean, and low flows of Turkish rivers has been investigated. Trend analysis has been carried out using the parametric $\mathrm{t}$ test and nonparametric (Mann-Kendall) test.

Kapor [18] analyzed the time series of hydrological data from 30 hydrological stations, which have a series of at least 50 years in water bodies belonging to the Danube river basin in the Republic of Serbia. The results indicate that the observed changes do not have a clearly defined trend.

The article presents a methodology for prediction of hydrological drought based on statistical testing of minimum monthly stream flows by non-parametric statistical test. The main objective is to identify low stream flow trends in selected 63 river stations in Eastern Slovakia in time interval 1975-2010. The Mann-Kendall non-parametric test has been used to detect trends in hydrological time series. Statistically significant trends have been determined from the trend lines and the prediction of hydrological drought risk in each month of hydrological year for the whole territory of Eastern Slovakia has been made. Using ArcView GIS, was created a graphical representation of hydrological drought risk. The aim of this contribution is to demonstrate a statistical analysis of low water flows for the purpose of evaluating the hydrological drought risk in selected river basins in the eastern part of Slovakia.

\section{MAteRIALS AND METHODS}

\section{A. Study Area}

Study area, as was mentioned, is situated at eastern part of Slovakia. In this territory 63 river stations are located (Fig. 1). Evaluated stations are divided at stations affected by human activity and without human influence. The affected river stations are considered as a station where the hydrological regime altered the flow by interference of human activities (by water works, by excessive water abstraction, etc.).

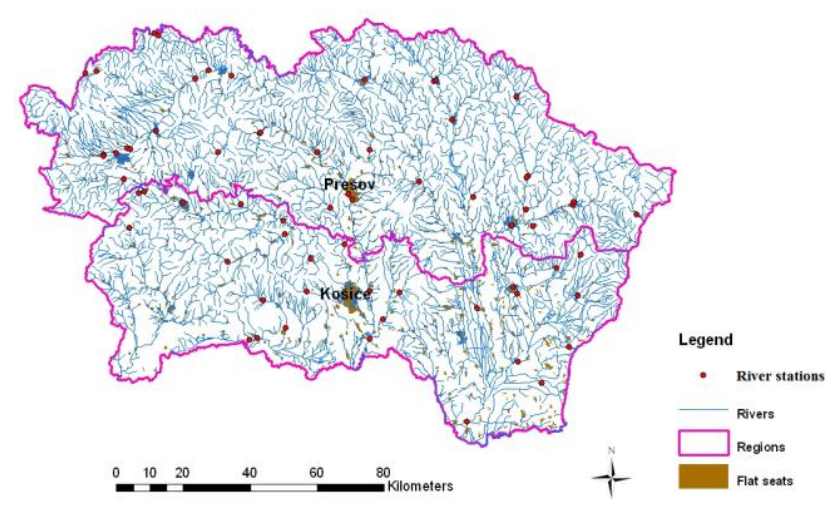

Fig. 1. A spatial distribution of river stations.

\section{B. Data}

The first step in the evaluation was to obtain values of the minimal monthly flow for selected river stations. Hydrological data were provided by Slovak Hydrometeorological Institute Regional Centre Košice, at monthly intervals during years 1975-2010.

\section{Statistical Analysis}

Basic datasets was created by chronologically ranking the values of low flows to the statistical files. One set of values is for one river station in mentioned 35-year period. This length of data set satisfies the required length in hydroclimatic time-series as proposed by Burn and Elnur [12]. In this study non-parametric Mann-Kendall test is used for the detection of the trend in a hydrological time series. The Mann-Kendall test is a non-parametric statistical test. That means that we needn't make any assumptions about distribution of the random variable. A statistical hypothesis is an assumption about the distribution of a random variable generally. A statistical test of the hypothesis is a procedure which is used to find out whether we may "not reject" ("accept") the hypothesis, that is, act as though it is true, or whether we should "reject" it, that is, act as though it is false. This statistical test has a variety of applications for trend analysis [15], [19], [20].

Mann-Kendall test is following statistics based on standard normal distribution (Z), by using Eq.(1).

$$
\begin{gathered}
Z=\left\{\begin{array}{ccc}
S-1 / \sqrt{\operatorname{Var}(S)} & \text { if } & S>0 \\
0 & \text { if } & S=0 \\
S+1 / \sqrt{\operatorname{Var}(S)} & \text { if } & S<0
\end{array}\right. \\
S=\sum_{k=1}^{n-1} \sum_{j=k+1}^{n} \operatorname{sgn}\left(x_{j}-x_{k}\right)
\end{gathered}
$$

$$
\operatorname{sgn}\left(x_{j}-x_{k}\right)=\left\{\begin{array}{lll}
+1 & \text { if } & \left(x_{j}-x_{k}\right)>0 \\
0 & \text { if } & \left(x_{j}-x_{k}\right)=0 \\
-1 & \text { if } & \left(x_{j}-x_{k}\right)<0
\end{array}\right.
$$

$$
\operatorname{Var}(S)=\left[n(n-1)(2 n+5)-\sum_{i=1}^{m} t(t-1)(2 t+5)\right] / 18
$$


where

$n$ is the number of data points,

$m$ is the number of tied groups (a set of sample data having the same value).

According to this test, the null hypothesis $\mathrm{H} 0$ states that the depersonalized data $\left(x_{1}, \ldots, x_{n}\right)$ is a sample of $n$ independent and identically distributed random variables. The alternative hypothesis $\mathrm{H} 1$ of a two-sided test is that the distributions of $x_{k}$ and $x_{j}$ are not identical for all $k, j \leq \mathrm{n}$ with $k \neq j$.

The value $\alpha$ is called the significance level; we choose $\alpha=$ 0.05 and $Z_{\alpha / 2}$ is a table value for normal distribution, in this case $Z_{\alpha / 2}=1.95996$. Hypothesis $\mathrm{H} 0$ - no trend is if $\left(Z<Z_{\alpha / 2}\right)$ and $\mathrm{H} 1$ - there is a trend if $Z>Z_{\alpha / 2}$. Moreover, the value of $Z$ gives further information about any increasing or decreasing of the trend, but not its magnitude exactly [17], [20].

The magnitude of the trend was determined using Sen`s estimator. Sen's method assumes a linear trend in the time series and has been widely used for determining the magnitude of trend in hydro-meteorological time series [15], [21]-[24]. In this method, the slopes $(\beta)$ of all data pairs are first calculated by

$$
\beta=\operatorname{Median}\left(\left(x_{j}-x_{k}\right) /(j-k)\right)
$$

for $i=1,2, \ldots, N$, where $x_{j}$ and $x_{k}$ are data values at time $j$ and $k(j>k)$, respectively and $N$ is a number of all pairs $x_{j}$ and $x_{k}$.

A positive value of $\beta$ indicates an upward (increasing) trend and a negative value indicates a downward (decreasing) trend in the time series.

All mathematical relations from (1) to (5) were programmed in Visual Basic in Microsoft Excel 2003 and sizes of significant trends in individual river stations were calculated in each month. Using ArcView GIS was created a graphical representation of analysis results.

\section{Results}

After the statistical analysis each river station is assigned trends of low flow in each month. Tables I to IV present statistically significant trends in the months with the favourable development water levels shown in double plus sign, if prevailing water levels drop are shown in double minus sign. Stations affected by human activity are highlighted in dark colour.

Evaluation of the trend analysis of the monthly stream flow series at 63 river stations in river basins Hornád, Poprad,
Bodva and Bodrog in the eastern Slovakia in 35 years' time period has been performed by the Mann-Kendall test. Percentage of decreasing trends in mentioned river basins for each month is presented in Table I. It was found that the river basins: Hornád and Bodva are most vulnerable to drought. The optimal regime of low flows is in those river basins: Poprad and Bodrog. Most of the decreasing trends of low flows in the streams in Eastern Slovakia in river catchments Poprad, Hornád, Bodva a Bodrog can be expected during summer months - May, June, July, and August as was proved by Mann Kendall test. In river stations affected by human activity are negative trends in water levels especially in Kysak, Brezovica, Ždaňa, Hostovce and in Michalovce Stráňany.

TABLE I: DECREASING TRENDS OF LOW FLOWS IN \% IN RIVER BASINS

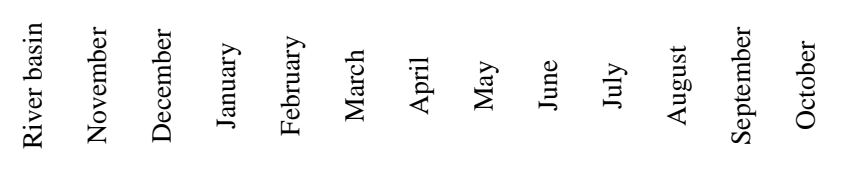

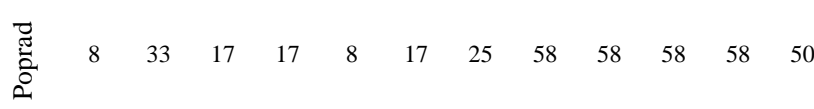

$$
\begin{aligned}
& \begin{array}{lllllllllllll}
\text { 苾 } & 24 & 29 & 38 & 43 & 48 & 57 & 81 & 81 & 62 & 29 & 38 & 24 \\
\text { 采 } & & & & & & & & & & & &
\end{array} \\
& \begin{array}{lllllllllllll}
\overbrace{0}^{2} & 80 & 40 & 40 & 80 & 80 & 100 & 100 & 100 & 100 & 100 & 80 & 80 \\
0 & & & & & & & & & & & &
\end{array}
\end{aligned}
$$

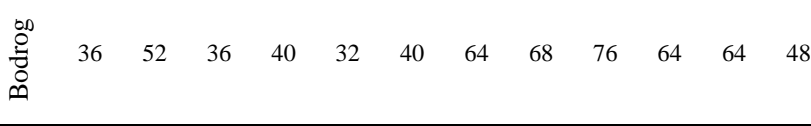

Hydrological drought regionalization is based on the obtained statistically significant trends and their sizes. The results of statistical analysis were recorded in the tabular in MS Excel and then exported to the ArcView GIS, which has been linked with a layer of "river station" means of identification numbers of stations. Maps of hydrological drought regionalization were created by spatial interpolation sizes of trends in individual months. Each map (Fig. 2) contains a schematic network of evaluated stations, and also the classification of hydrological drought regionalization which has four levels: high, medium, low and no risk of hydrological drought. Classification was obtained from the output intervals incurred in the interpolation entry data.
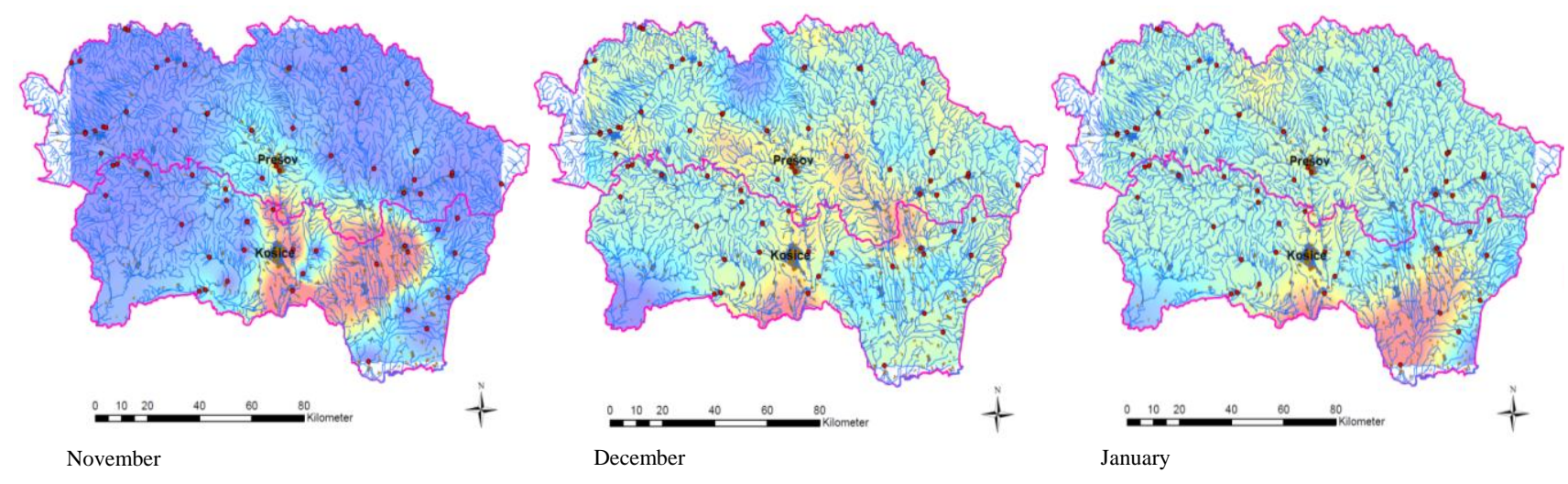

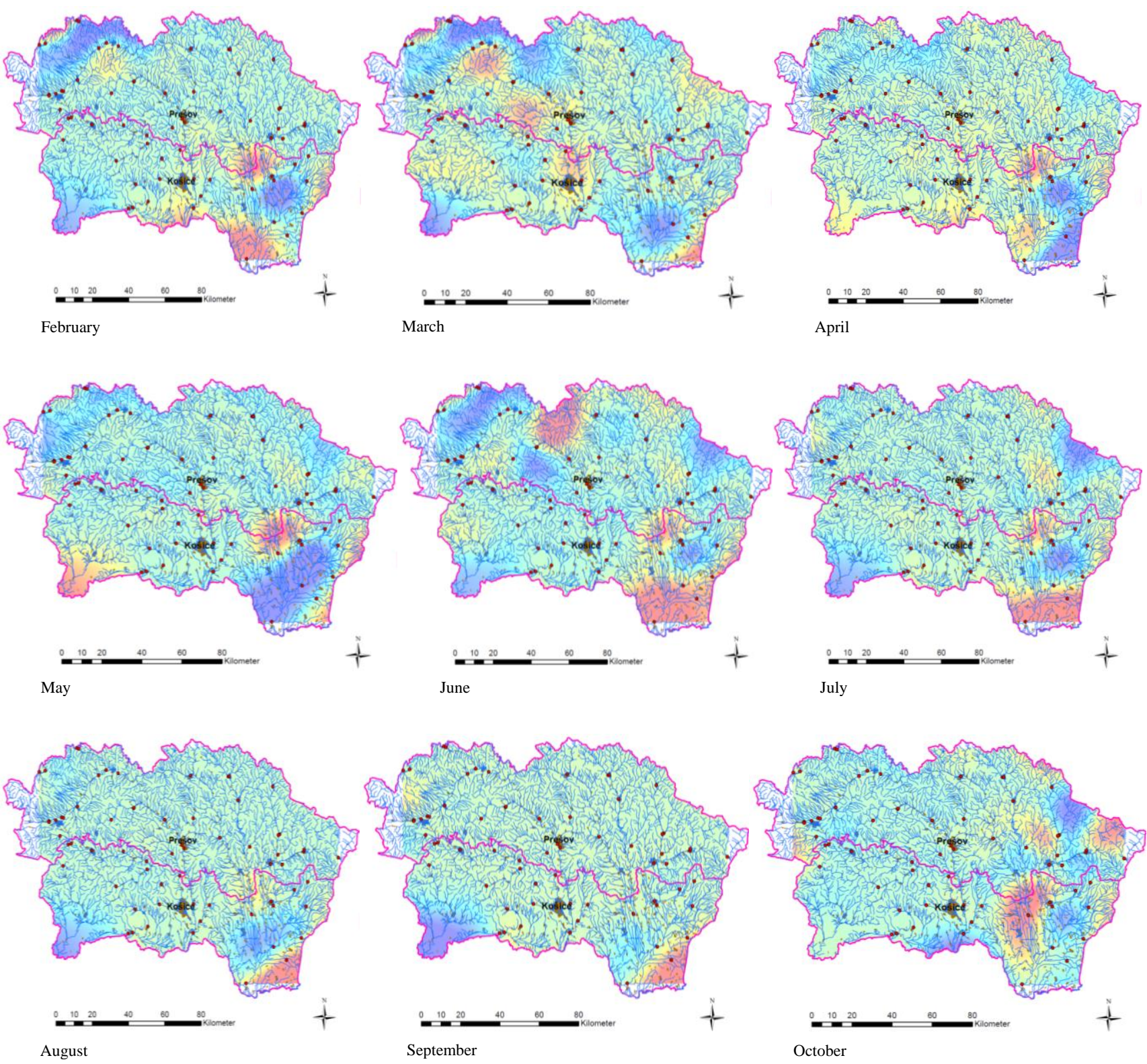

Fig. 2. Hydrological drought risk regionalization in Eastern Slovakia.

\section{CONCLUSION}

Hydrological drought analyses in terms of stream flow deficits are said to be studies over a season or longer time periods and in a regional context. A stream flow drought event definition quantitatively defines whether the flow can be regarded as being in a drought situation or not and gives the duration of a drought, whereas low flow indices characterise specific features of the low flow range.

The article presents a methodology for prediction of hydrological drought risk based on statistical testing of flow characteristics of low water content (minimum monthly stream flow) with non-parametric statistical test. The main objective was to identify low flow trends in the selected 63 river stations in Eastern Slovakia in time period 1975-2010. The Mann-Kendall non-parametric test was used to detect trends in hydrological time series. Statistically significant trends have been determined from the trend lines and the prediction of hydrological drought risk regionalization in each month of hydrological year for the whole territory of Eastern Slovakia was made. Some of stream flow records in rivers in Eastern Slovakia are affected by human activities and another are without its influence.

Statistical tests can detect the existence of trends in hydrological time series. The purpose of the tests is to detect a statistically significant trend of decrease or increase of low flow values. Non-parametric Mann-Kendall test doesn't make assumption on the probability distribution of random variable. It has wide application in testing of hydro-meteorological characteristics.

The results confirmed the rising incidence trends of decreasing of low flows in the streams in Eastern Slovakia in river catchments Poprad, Hornád, Bodva a Bodrog. Hydrological drought can be expected in almost summer months during the year - May, June, July, and August. This methodology was used in the risk analysis of hydrological drought in individual regions. In the complex vulnerability assessment of territory owing to drought is essential to take into account also the parameters as temperature, precipitation and groundwater levels.

Using ArcView GIS was created a graphical representation of hydrological drought risk regionalization in 
each month of the hydrological year.

The contribution is written thanks to support of project VEGA 1/0609/14.

\section{REFERENCES}

[1] K. Mishra and P. Singh, "A review of drought concepts," J. Hydrol., vol. 263, pp. 203-212, 2010.

[2] D. A. Wilhite, Drought: A Global Assessment, vol. 1-2, New York, US Routledge, 2000

[3] World Meteorological Organization (WMO), Guide to Hydrological Practices No 1211/168 on Hydrology - from Measurement to Hydrological Information, vol. 1, Switzerland: World Meteorological Organization, 2008.

[4] J. Korytárová, M. Šlezingr, and H. Uhmannová, "Determination of potential damage to representatives of real estate property in areas afflicted by flooding," J. Hydrol. Hydromech., vol. 55, pp. 282-285, 2007.

[5] P. Pelikán and M. Šlezingr, "Methodology for the establishment of physical and geometric properties of a drainage basin," Acta. Univ. Agric. Et Silvic. Mendel. Brunen., vol. 59, pp. 265-270, 2011.

[6] B. Demeterová and P. Škoda, "Low flow in selected streams of Slovakia (in Slovak)," J. Hydrol. Hydromech., vol. 57, pp. 55-59, 2008

[7] J. Szolgay, M. Dzubák, and K. Hlavčová, "Hydrology. Runoff process and hydrology of surface water (in Slovak)," Bratislava, SK: Slovak Technical University, 1994.

[8] B. Demeterová, P. Škoda, R. Magulová, V. Gápelová, B. Síčová, and S. Liová, "Hydrological limits. Low water content, Analysis of water balance in drought year with a new flow limits (in Slovak)," Task of SHMI 6321-00, Final report - part 2, Bratislava, SK: Slovak Hydrometeorological Institute, 2006.

[9] H. Hisdal and L. M. Tallaksen, Impact of Droughts in Europe, Drought Event Definition, Technical Report No. 6, 2000.

[10] H. Hisdal, K. Stahl, L. Tallaksen, and S. Demuth, "Have streamflow droughts in Europe become more severe or frequent?" Int. J. Climatol., vol. 21, pp. 317-333, 2001.

[11] R. M. Hirsch, R. B. Alexander, and R. A. Smith, "Selection of methods for the detection and estimation of trends in water quality," Water Resour. Res., vol. 27, pp. 803-813, 1991.

[12] D. H. Burn and M. A. H. Elnur, "Detection of hydrologic trends and variability," J. Hydrol., vol. 255, pp. 107-122, 2002.

[13] M. G. Kendall, Rank Correlation Measures, London, UK: Charles Griffin, 1975.

[14] H. B. Mann, "Non-parametric tests against trend," Econometrica, vol. 13, pp. 245-259, 1945.

[15] K. Stahl, H. Hisdal, J. Hannaford, L. Tallaksen, H. Van Lanen, E. Sauquet, S. Demuth, M. Fendekova, and J. Jordar, "Streamflow trends in Europe: evidence from a dataset of near-natural catchments," Hydrol. Earth Syst. Sci., vol. 14, pp. 2367-2382, 2010.

[16] E. M. Douglas, R. M. Vogel, and C. N. Kroll, "Trends in floods and lowflows in the United States: impact of spatial correlation," $J$ Hydrol., vol. 255, pp. 107-122, 2002.

[17] B. Önöz and M. Bayazit, "The Power of Statistical Tests for Trend Detection," Turkish J. Eng. Env. Sci., vol. 27, pp. 247-251, 2003.

[18] B. Kapor, S. Marjanovic, and S. Catovic. (2011). On the Analysis of Trends of Average Flow on Watercourses in Serbia which belong to the Danube River Basin. [Online]. Available: http://152.66.18.61/Floodrisk/_DC/docs/4_26_prohaska.pdf

[19] T. Partal and E. Kahya, "Trend analysis in Turkish precipitation data," Hydrological Processes, vol. 20, pp. 2011-2026, 2006.

[20] J. F. Santos, I. Pulido-Calvo, and M. M. Portela, "Spatial and temporal variability of droughts in Portugal," Water Resour. Res., vol. 46, W03503, 2010.

[21] P. K. Sen, "Estimates of the regression coefficient based on Kendall's tau," Journal of the American Statistical Association, vol. 63, pp. 1379-1389, 1968.

[22] P. Štavina, Algoritms of Scientific and Technical Computations (in Slovak). Bratislava, SK: Comenius University, 2010.

[23] S. Yue and M. Hashino, "Temperature trends in Japan: 1900-1990," Theoretical and Applied Climatology, vol. 75, pp. 15-27, 2003.

[24] D. P. Lettenmaier, E. F. Wood, and J. R. Wallis, "Hydro-climatological trends in the continental United States 1948-88," J. of Climate, vol. 7, pp. 586-607, 1994.

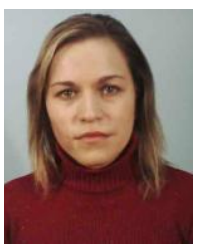

Martina Zeleňáková is an assistant professor at Institute of Environmental Engineering at Civil Engineering Faculty, Technical University of Košice. She is oriented on the field of water management and environmental risks in her scientific-research work. She publishes results of her work in journals and scientific proceedings from Slovak and abroad conferences.

Pavol Purcz is an assistant professor at Institute of Construction Technology and Management at Civil Engineering Faculty, Technical University of Košice. He teaches mathematics and is interested in the field of mathematical statistic.

Tatiana Sol'áková is a $\mathrm{PhD}$ student at Institute of Environmental Engineering at Civil Engineering Faculty, Technical University of Košice. Her thesis is focused to drought risk management. 